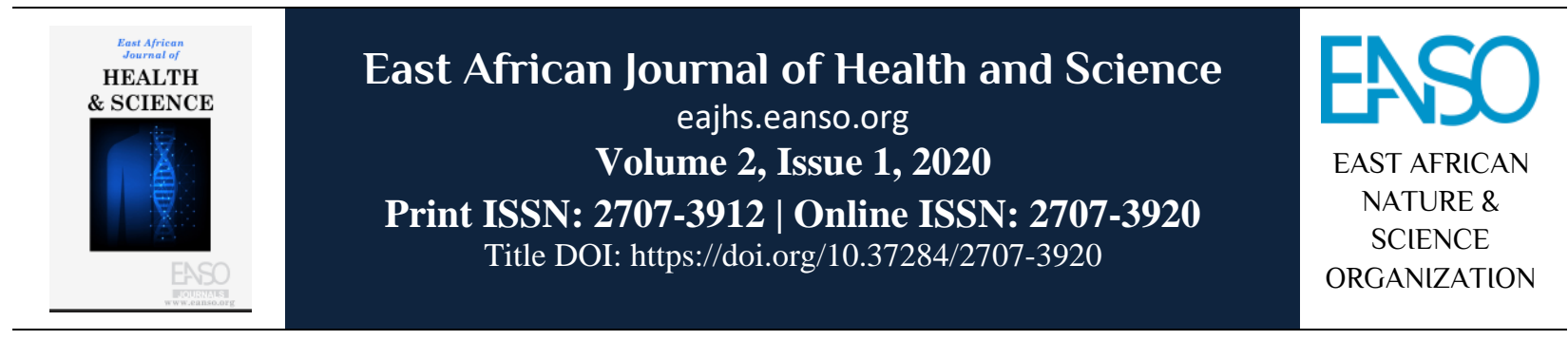

Original Article

\title{
Influence of Social Cultural Factors on HIV Seropositivity Disclosure to Sexual Partners in Kenya
}

\author{
Phoebe D. Ndayala, $P h D^{1} \&$ Lucy W. Ngige, PhD ${ }^{*, 2}$ \\ ${ }^{1}$ Kenyatta University, P. O. Box 43844 - 00100, Nairobi, Kenya; ORCID: https://orcid.org/0000-0002-2406-8989. \\ ${ }^{2}$ Kenyatta University, P. O. Box 43844 - 00100, Nairobi, Kenya; ORCID: https://orcid.org/0000-0003-1750-1496. \\ *Author for correspondence email: ngigelucy@gmail.com.
}

Article DOI: https://doi.org/10.37284/eajhs.2.1.224

\section{Date Published: ABSTRACT}

14 October 2020 The purpose of the study was to assess whether sociocultural factors have an influence on the self-disclosure of HIV serostatus to intimate partners among Keywords: People Living with HIV and AIDS (PLWHA). A survey was conducted among 232 HIV and AIDS, Cultural Barriers, Customary Beliefs, Sexual Behaviour, HIV Serostatus, Self-Disclosure. randomly selected respondents who were HIV seropositive and were members of a registered community-based support group for PLWHA in Nairobi, Kenya. Data was gathered by means of semi-structured interviews and focus group discussions. Results revealed that the marital status of the respondents varied from never married (13.4\%), married (27.6\%), separated (26.3\%), divorced (4.3\%) and widowed $(28.4 \%)$. Approximately half of the respondents $(50.4 \%)$ had disclosed their HIV serostatus to their intimate partners while $49.6 \%$ had not. The binary logistic regression results established that some socio-cultural factors fostered HIV seropositivity disclosure while others did not. The positive predictors of HIV serostatus disclosure were gender inequalities in the sexual relationship ( $\mathrm{AOR}=4.129 ; \mathrm{p}=0.011$ ), the role of females as dependent housewives (AOR=1.322; $\mathrm{P}=0.004)$, anticipated divorce following $\mathrm{HIV}$ disclosure $(\mathrm{AOR}=2.578 ; \mathrm{p}=0.014)$ and the cultural belief that HIV was a curse $(\mathrm{AOR}=2.444$; $\mathrm{p}=0.005)$. However, sexual behaviour such as homosexuality, rape, incest, sex with minors and extramarital sex $(\mathrm{AOR}=0.225 ; \mathrm{p}=0.001)$, intimate partner violence $(\mathrm{AOR}=0.220 ; \mathrm{p}=0.001)$, the subordination of females by their male partners (AOR=0.351; $\mathrm{p}=0.002$ ) and the fear of exclusion from the cultural rite of wife inheritance during widowhood ( $\mathrm{AOR}=0.410 ; \mathrm{p}=0.002)$ were negative predictors of disclosure of HIV serostatus. This implies that there was no likelihood of HIV disclosure, thereby putting intimate partners at risk of HIV infection. It was recommended that there was the need to promote community discourse on HIV and AIDS in order to reduce the socio-cultural barriers to self-disclosure of HIV 
seropositive status and to increase the community acceptance of people living with HIV and AIDS.

\section{APA CITATION}

Ngige, L., \& Ndayala, P. (2020). Effects of Anticipated Stigma and Discrimination on Self-Disclosure of HIV Seropositive Status among People Living with HIV and AIDS in Kenya. East African Journal of Health and Science, 2(1), 62-74. https://doi.org/10.37284/eajhs.2.1.224.

\section{CHICAGO CITATION}

Ngige, Lucy, and Phoebe Ndayala. 2020. "Effects of Anticipated Stigma and Discrimination on Self-Disclosure of HIV Seropositive Status among People Living with HIV and AIDS in Kenya". East African Journal of Health and Science 2 (1), 6274. https://doi.org/10.37284/eajhs.2.1.224.

\section{HARVARD CITATION}

Ngige, L. and Ndayala, P. (2020) "Effects of Anticipated Stigma and Discrimination on Self-Disclosure of HIV Seropositive Status among People Living with HIV and AIDS in Kenya", East African Journal of Health and Science, 2(1), pp. 62-74. doi: 10.37284/eajhs.2.1.224.

\section{IEEE CITATION}

L. Ngige and P. Ndayala, "Effects of Anticipated Stigma and Discrimination on Self-Disclosure of HIV Seropositive Status among People Living with HIV and AIDS in Kenya", EAJHS, vol. 2, no. 1, pp. 62-74, Sep. 2020.

\section{MLA CITATION}

Ngige, Lucy, and Phoebe Ndayala. "Effects of Anticipated Stigma and Discrimination on Self-Disclosure of HIV Seropositive Status among People Living with HIV and AIDS in Kenya". East African Journal of Health and Science, Vol. 2, no. 1, September 2020, pp. 62-74, doi:10.37284/eajhs.2.1.224.

\section{INTRODUCTION}

According to UNAIDS (2020), HIV is a global public health issue with an estimated 75.7 million people becoming infected with HIV since the epidemic started in June 1981, and approximately 33 million individuals having died from AIDSrelated illnesses. Of the 38 million PLWHA globally, about $81 \%$ knew their HIV status, and the rest $19 \%$ did not know that they were living with HIV. However, with increasing access to effective HIV prevention, diagnosis, treatment and care, HIV infection is a manageable chronic health condition, enabling people living with HIV to lead long and healthy lives. In spite of this, there are challenges facing PLWHA in terms of health beliefs, sexual behaviour and self-disclosure of HIV serostatus to intimate partners. According to a UNESCO (2011) report, control over people's sexual lives and choices is shaped by culture and gender norms defining masculinity and femininity which evolve through the socialization process from early childhood. Consequently, many PLWHA are compelled by their socio-cultural contexts not to disclose their HIV statuses. This inevitably reduces their ability to engage in HIV preventive behaviour or to obtain social support for coping with their HIV serostatus. These sociocultural barriers can make PLWHA progress to AIDS and eventually to an early death (Norman et al., 2005). Research by Mbonu, Borne and De Vries in 2009, found that the cultural constructions of HIV and AIDS based on beliefs about contamination, sexuality and religion, promotes stigma and discrimination against PLWHA in the community.

According to Wiener, Battles and Wood (2007), some societies believe that once individuals are infected with HIV and AIDS, they are considered to be the "reservoir" which propagates and spreads the virus to others. The social discourses on HIV and AIDS are of the view that the condition infects a particular category of people in society, thereby moralizing HIV and AIDS as a consequence of sexual permissiveness and moral decadence. This socio-cultural perception of HIV may keep PLWHA from disclosing their HIV serostatus to significant others. Research by Ogden and Nyblade (2005) has established that cultural stigma and sexual taboos have inverse relationships with selfdisclosure of HIV serostatus. Furthermore, it has been demonstrated that cultural stigma varies by ethnicity and gender. Women living with HIV and AIDS tend to be more highly stigmatised than their 
male counterparts due to the belief that HIV is acquired through sexually decadent behaviours. According to Kim et al. (2007), there is a social expectation in many communities that women should uphold sexual morality while men can be more sexually permissive without any social ramifications.

According to the UNAIDS (2020) Global report on HIV and AIDS epidemic, HIV continues to be driven by gender inequalities and harmful gender norms that promote unsafe sex and reduce access to sexual and reproductive health services for men, women and transgender persons. Women are disproportionately affected by the HIV epidemic in Sub-Sahara Africa accounting for $57 \%$ of all PLWHA. Furthermore, Varga et al. (2006) report that women are at high risk for HIV infection and yet, their access to HIV counselling and testing services is often limited by stigma, social and gender norms that dictate women's sexual and reproductive behaviour. According to Kesby (2004), men, in general, have higher gender power and control in sexual relationships compared to women, and this may influence the decisionmaking patterns in other spheres of life. Research has established that gender inequalities make women and girls more vulnerable to rape, incest and sex with minors Research by Leclerc-Madlala (2008) and UNESCO (2011) has established that gender inequalities promotes unequal access to education and decreases women's economic opportunities. Furthermore, the fear of abuse and violence meted against women and girls undermine their capacity to negotiate for safer sex (Walcott et al., 2013; Ndiaye, 2008). A study by Varga et al. (2006) exploring the association between HIV infection, serostatus disclosure, and partner violence among women attending a VCT clinic in Tanzania found that women lacked the autonomy to make decisions about HIV testing because they were expected to "seek permission" from their male partners prior to testing, while conversely, men made the decision to go for HIV testing without soliciting their female partners' consent. Moreover, HIV serostatus disclosure by women was meted with violence by their male partners.
Disclosure of HIV status to significant others may result in negative consequences such as stigma and discrimination against PLWHA. Several studies have indicated that PLWHA may suffer from rejection and other psychological problems by their intimate partners as well as financial insecurity $(\mathrm{Vu}$, 2012; Serovich, 2008). Self-disclosure of HIV serostatus has potential risks such as physical and emotional violence, desertion by intimate partners and abandonment by close family members (Walcott et al., 2013). PLWHA who perceive a stigmatising environment may be reluctant to disclose their HIV serostatus to others, thereby putting their intimate partners at risk of HIV infection (Simbayi et al., 2006). Previous studies have reported that stigma and discrimination adversely affect disclosure to intimate partners and significant others. (Smith, Rossetto, Brittany \& Peterson, 2008; Wolfe et al., 2006). A survey conducted in Botswana by Wolfe et al. (2006), found that about half of the patients delayed getting tested for HIV due to fear of stigma. Researchers have also connected stigma and discrimination with postponing or rejecting care and travelling outside the local community for care due to fear of lack of confidentiality by health care providers. (Liu et al., 2006). A study carried out in Kenya by Turan (2008) among pregnant women found that fears of negative male partner reactions, especially domestic violence and rejection were important influences on women's decision on HIV prevention strategies. In addition, HIV positive status disclosure has been associated with job loss. A study by Ngula and Miller (2010) among men in Eastern Kenya showed that many men feared losing their jobs after HIV seropositive status disclosure.

Research by Turan et al. (2008) among pregnant women in Kenya indicated that fears and experiences of stigma and discrimination from health workers, male partners, family and community members have been identified as potential explanations for the facts that some pregnant women avoid maternity services including antenatal HIV testing. Another study carried out among pregnant women in Nyanza, Kenya found that fears of negative male partner reactions were important influences on women's decision regarding HIV testing. A study carried out by Action Aid International Kenya (2009) on stigma and discrimination among PLWHA in Western 
Kenya established that the fear of HIV transmission through the caregiving activities for PLWHA led to stigma. The study reported the impact of stigma included loss of livelihood, loss of marriages and the subsequent burden of single parenthood. The study concluded that cultural stigma and discrimination complicates decisions about HIV testing, disclosure of HIV serostatus, and ability to negotiate HIV preventive behaviour. There are gaps in knowledge of the social and cultural factors that influence the self-disclosure of HIV serostatus to intimate partners among PLWHA. Therefore, the objective of this study was to assess whether sociocultural factors influenced the self-disclosure of HIV serostatus to intimate partners among PLWHA. The null hypothesis posited that sociocultural factors did not predict the self-disclosure of HIV serostatus to intimate partners among PLWHA.

\section{METHODOLOGY}

A survey was conducted among 232 randomly selected respondents who were HIV seropositive and were members of a community-based support group for PLWHA in Nairobi, Kenya. Data were gathered by means of a semi-structured interview and focus group discussion. The independent variables were socio-cultural factors that influenced the self-disclosure of HIV statuses such as marital status, gender roles, sexual behaviour and cultural beliefs about the causes of HIV. These variables were measured by asking the respondents their perceptions about gender roles, causes of HIV and AIDS, sexual taboos and sanctions meted against PLWHA in the community. The dependent variable was self-disclosure of HIV serostatus to intimate partners by PLWHA. Ethical approvals to conduct research were granted by the relevant research authorities and informed written consent was obtained from the study participants prior to the study. The Cronbach alpha measure of internal consistency for all research items ranged from 0.70 to 0.82 . Data was analysed by the use of the Statistical Package for the Social Sciences (SPSS Version 24).

\section{RESULTS}

The distribution of marital status, gender roles and disclosure of HIV serostatus are presented in Table 1.

Table 1: Distribution of Marital Status, Gender Roles and HIV Disclosure

\begin{tabular}{llc}
\hline Variable & Frequency & Percent (\%) \\
\hline Marital Status (N=232) & 31 & 13.4 \\
Never married (Single) & 64 & 27.6 \\
Married & 61 & 26.3 \\
Separated & 10 & 4.3 \\
Divorced & 66 & 28.4 \\
Widowed & & \\
Men's' Gender Roles* & 210 & 90.5 \\
Family Provider & 197 & 85.0 \\
Decision maker & 191 & 82.3 \\
Husband/Father & 173 & 74.5 \\
Household head & & \\
Women's Gender Roles* & 193 & 83.2 \\
Wife/Mother & 194 & 83.6 \\
Dependent Housewife & 211 & 90.9 \\
Family caregiver & 160 & 69.0 \\
Submissive to the husband & 67 & 29.0 \\
Discipline of the children &
\end{tabular}




\begin{tabular}{llll}
\hline Variable & Frequency & Percent (\%) & \\
\hline HIV Disclosure by Gender* & & & \\
Variable & Males & Females & Total \\
Disclosure of HIV Serostatus & 28 & 89 & $\mathbf{1 1 7}$ \\
& $(43.1 \%)$ & $(53.3 \%)$ & $\mathbf{( 5 0 . 4 \% )}$ \\
Non-Disclosure HIV Serostatus & 37 & 78 & $\mathbf{1 1 5}$ \\
& $(53.9 \%)$ & $(46.7 \%)$ & $\mathbf{( 4 9 . 6 \% )}$ \\
Total & $\mathbf{6 5}$ & $\mathbf{1 6 7}$ & $\mathbf{2 3 2}$ \\
& $\mathbf{( 1 0 0 . 0 \% )}$ & $\mathbf{( 1 0 0 . 0 \% )}$ & $\mathbf{( 1 0 0 . 0 \% )}$ \\
\hline
\end{tabular}

*Multiple responses included

Results presented in Table 1 revealed that the marital statuses of the respondents were $13.4 \%$ never married, $27.6 \%$ married, $26.3 \%$ separated, $4.3 \%$ divorced and $28.4 \%$ widowed. The findings established that a high proportion of the study participants $(72.4 \%)$ were currently not living with their regular sexual partners. During focus group discussion, some of the participants reported that their intimate partners had died as a result of AIDSrelated illnesses, while others had been deserted by their partners after disclosure of their HIV seropositive status.

Men and women are expected to take different roles in many African cultures. Culturally the respondents expected the males to provide for the family $(90.5 \%)$, marry a wife and sire children $(82.3 \%)$, be the family decision-maker $(85.0 \%)$ and head of the family $(74.5 \%)$. The respondents reported that females were expected to marry and have children $(83.2 \%)$, care for their family members $(90.9 \%)$, be submissive to their husbands/intimate partners $(69 \%)$, to discipline their children (29\%). and to be full-time housewives dependent on their husbands or male partners $(83.6 \%)$. The results demonstrated that respondents had gender-specific roles that they were expected to play in relation to their intimate partners and in the community.

In terms of HIV seropositivity disclosure, results revealed that $50.4 \%$ of the respondents had disclosed their HIV serostatus to their intimate partners while $49.6 \%$ had not. There was a variance in the proportion of disclosure rates by gender. The female respondents were more likely to disclose $(53.3 \%)$ their HIV seropositive status to intimate partners than their male counterparts $(43.1 \%)$. This finding is supported by the results from the focus group discussion which revealed that a large proportion of the male respondents were the main breadwinners for their households. This could be attributed to the fact that females were dependent on their male partners and therefore there was a need for them to disclose their HIV serostatus in order to have continued access to medical and financial support.

\section{Perceptions of Sexual Behaviour, Causes of HIV and Sanctions against PLWHA}

The results of the perceptions of sexual taboos, cultural beliefs of the causes of HIV and the sanctions meted against PLWHA are presented in Table 2.

Table 2: Distribution of Sexual Behaviour, Beliefs about HIV and Sanctions against PLWHA

\begin{tabular}{lll}
\hline Sexual Behaviour by Gender & & \\
\hline Variable & Males (\%) & Females (\%) \\
Incest & 94.4 & 89.6 \\
Homosexuality/Lesbianism & 77.9 & 59.0 \\
Rape & 52.0 & 45.0 \\
Sex with minors & 44.0 & 34.0 \\
Extramarital sex & 31.0 & 28.0
\end{tabular}




\begin{tabular}{lll}
\hline $\begin{array}{l}\text { Causes of HIV Infection } \\
\text { Variable }\end{array}$ & Frequency & Percent \\
HIV is caused by sexual immorality & 97 & 41.8 \\
HIV is punishment for past mistakes & 93 & 40.1 \\
HIV is a death sentence & 56 & 24.1 \\
HIV is caused by a curse & 54 & 23.2 \\
HIV is a contagious disease & 47 & 20.3 \\
Cultural Sanctions against PLWHA & & \\
Variable & Frequency & Percent \\
Desertion by intimate partner & 161 & 69.4 \\
Intimate partner violence & 149 & 64.3 \\
Abandonment by the family/in-laws & 118 & 50.9 \\
Exclusion from the rite of wife inheritance & 128 & 55.2 \\
Denial of child custody & 35 & 15.0 \\
Discrimination of children of PLWHA & 154 & 66.7 \\
Exclusion from social and community functions & 158 & 68.4 \\
\hline
\end{tabular}

Multiple responses included

The results revealed that the respondents practised a variety of sexual behaviours. The sexual behaviours reported by male respondents were incest $(94.4 \%)$, homosexuality $(77.9 \%)$, sex with minors $(44 \%)$, rape $(52 \%)$ and extramarital sex (31\%). The sexual behaviours reported by female respondents were incest $(89.6 \%)$, lesbianism $(59 \%)$, rape $(45 \%)$, sex with minors $(34 \%)$ and extramarital sex $(28 \%)$. The findings established that majority of the study participants practised incest, homosexuality and lesbianism, while about half had experienced rape and about one-third had sex with a minor or extramarital sex. During focus group discussions, the participants agreed that these sexual behaviours were considered as sexual taboos in the community.

The cultural beliefs about the causes of HIV infection influence the way PLWHA are treated by others, which may in turn affect their decision on whether to disclose their HIV status to others or not. The results showed that the respondents believed that HIV was caused by sexual immorality (41.8\%), punishment for past mistakes (40.1\%), death sentence $(24.1 \%)$, a curse $(23.2 \%)$ and contagious disease $(20.3 \%)$. These results revealed that there was misinformation about the causes of HIV infection among PLWHA. Results showed that the cultural sanctions against PLWHA included desertion by spouse or intimate partner $(69.4 \%)$, domestic violence (64.3\%), abandonment by family and in-laws $(50.9 \%)$, exclusion from the cultural rite of wife inheritance during widowhood $(55.2 \%)$, denial of custody of one's children (15.0\%), discrimination of children of PLWHA by the next of kin $(66.7 \%)$ and exclusion from the community and social functions. These results implied that cultural sanctions meted against PLWHA were so severe that respondents felt discouraged in disclosing their HIV serostatus to sexual partners.

\section{Hypothesis Test Results}

The null hypothesis posited that socio-cultural factors do not have any statistically significant relationship to the self-disclosure of HIV serostatus among PLWHA. The results for the Chi-square results are presented in Table 3.

Table 3: Chi-Square Results for Socio-Cultural factors and HIV Status Disclosure

\begin{tabular}{llll}
\hline Variable & $\begin{array}{l}\text { Chi- } \\
\text { square } \\
\left(\chi^{2}\right)\end{array}$ & $\begin{array}{l}\text { Degree of } \\
\text { Freedom } \\
\text { (df) }\end{array}$ & $\begin{array}{l}\text { Significance } \\
\text { (p-value) }\end{array}$ \\
Sex of the respondent & 1.954 & 1 & 0.162 \\
Gender inequality & 6.706 & 1 & 0.101 \\
Female subordination to husbands/intimate partners & 6.413 & 1 & $0.011^{*}$
\end{tabular}




\begin{tabular}{|c|c|c|c|}
\hline Variable & $\begin{array}{l}\text { Chi- } \\
\text { square } \\
\left(\chi^{2}\right)\end{array}$ & $\begin{array}{l}\text { Degree of } \\
\text { Freedom } \\
\text { (df) }\end{array}$ & $\begin{array}{l}\text { Significance } \\
\text { (p-value) }\end{array}$ \\
\hline Dependent housewives & 13.385 & 1 & $0.001 *$ \\
\hline Intimate partner violence & 9.753 & 1 & $0.002 *$ \\
\hline Desertion by intimate partner & 5.450 & 1 & $0.020^{*}$ \\
\hline Exclusion from the rite of wife inheritance & 9.555 & 1 & $0.002 *$ \\
\hline $\begin{array}{l}\text { Sexual behaviours associated with males } \\
\text { (homosexuality, rape, incest, sex with minors) }\end{array}$ & 5.450 & 1 & $0.001 *$ \\
\hline $\begin{array}{l}\text { Sexual behaviours associated with females } \\
\text { (lesbianism, incest, extramarital sex) }\end{array}$ & 11.909 & 1 & $0.001 *$ \\
\hline Belief that HIV is a curse & 5.744 & 1 & $0.017 *$ \\
\hline Belief that HIV is a punishment for past mistakes & 2.527 & 1 & 0.112 \\
\hline Belief that HIV is a contagious disease & 1.572 & 1 & 0.210 \\
\hline Belief that HIV is a death sentence & 5.387 & 1 & $0.020 *$ \\
\hline
\end{tabular}

*Significant at $\mathrm{p} \leq 0.05$

The Chi-square results revealed that gender roles, sexual taboos and cultural beliefs about the causes of HIV were significantly associated with HIV seropositivity disclosure to intimate partners. The gender roles that had a significant relationship with disclosure included the subordination of females to their spouses or intimate partners $\left(\chi^{2}=6.413, \mathrm{df}=1\right.$, $\mathrm{p}=0.110)$, dependent housewives $\left(\chi^{2}=13.385, \mathrm{df}=1\right.$, $\mathrm{p}=0.001)$, desertion by intimate partner $\left(\chi^{2}=5.450\right.$, $\mathrm{df}=1, \quad \mathrm{p}=0.020)$, intimate partner violence, specifically wife-beating $\left(\chi^{2}=9.753, \mathrm{df}=1\right.$, $\mathrm{p}=0.002$ ) and exclusion from the rite of wife inheritance of the respondents who were HIV seropositive The sexual taboos that were significantly related to self-disclosure of HIV serostatus were incest $\left(\chi^{2}=15.797, \mathrm{df}=1, \mathrm{p}=0.001\right)$, rape $\left(\chi^{2}=5.450, \mathrm{df}=1, \mathrm{p}=0.001\right)$, homosexuality $\left(\chi^{2}\right.$ $=14.167, \mathrm{df}=1, \mathrm{p}=0.001)$ and extramarital sex $\left(\left(\chi^{2}\right.\right.$ $=11.909, \mathrm{df}=1, \mathrm{p}=0.001)$. Results further revealed that the cultural beliefs about the causes of HIV infection significantly influenced the selfdisclosure of HIV serostatus among PLWHA.
These factors included the belief that HIV is caused by a curse related to someone's past behaviour $\left(\chi^{2}\right.$ $=5.744, \mathrm{df}=1, \mathrm{p}=0.017)$ and the belief that HIV infection is a death sentence $\left(\chi^{2}=5.387, \mathrm{df}=1\right.$, $\mathrm{p}=0.020)$. However, the Chi-square results indicated that the sex of the respondent $\left(\chi^{2}=1.954\right.$, $\mathrm{df}=1, \mathrm{p}=0.162)$, gender inequality $\left(\chi^{2}=6.706, \mathrm{df}=1\right.$, $\mathrm{p}=0.101$ ), HIV as a punishment for mistakes committed in the past $\left(\chi^{2}=2.527, \mathrm{df}=1, \mathrm{p}=0.112\right)$ and HIV as a contagious disease $\left(\chi^{2}=1.572, \mathrm{df}=1\right.$, $\mathrm{p}=0.210$ ) were not significantly associated with HIV self-disclosure to intimate partners.

\section{Predictors of HIV Self-Disclosure to Intimate Partners}

Further analysis using Binary Logistic Regression test was used to establish the predictors of selfdisclosure of HIV serostatus among PLWHA. The results of the prediction results are presented in Table 4.

Table 4: Predictors of Disclosure of HIV Serostatus

\begin{tabular}{llll}
\hline Variable & AOR & P-Value & 95\% CI \\
\hline Gender inequality in the sexual relationships & 4.129 & $0.011^{*}$ & $1.376-12.389$ \\
Female subordination to husband/male partner & 0.351 & $0.002^{*}$ & $1.0181-0.0682$ \\
Role of women as dependent housewives & 1.322 & $0.004^{*}$ & $0.219-0.725$ \\
Desertion of intimate partner & 0.539 & 0.086 & $0.272-1.066$ \\
Intimate Partner Violence (wife beating) & 0.220 & $0.001^{*}$ & $1.105-0.460$ \\
Divorce after disclosure & 2.578 & $0.014^{*}$ & $1.216-5.446$ \\
Exclusion from the rite of wife inheritance & 0.410 & $0.002^{*}$ & $0.181-0.782$ \\
Sexual taboos associated with male sexual behaviour & 0.225 & $0.001^{*}$ & $0.103-0.493$
\end{tabular}




\begin{tabular}{llll}
\hline Variable & AOR & P-Value & 95\% CI \\
\hline Sexual taboos associated with female sexual behaviour & 2.746 & 0.191 & $0.604-12.481$ \\
Belief that HIV is caused by a curse & 2.441 & $0.005^{*}$ & $0.997-2.140$ \\
Belief that HIV is a death sentence & 0.530 & 0.076 & $0.272-1.066$ \\
\hline
\end{tabular}

*significant predictors at $\mathrm{p} \leq 0.05$

The results presented in Table 4. revealed that among the sociocultural factors tested, there were both positive predictors with an Adjusted Odd Ratio (AOR) of more than one (AOR $\geq 1.000)$ as well as negative predictors with an Adjusted Odd Ratio of less than one $(A O R \leq 1.000)$. The variables that were positive predictors of HIV seropositivity disclosure were gender inequalities in the sexual relationship (AOR=4.129; $\mathrm{p}=0.011$ ), the role of women as dependent housewives $(\mathrm{AOR}=1.322$; $\mathrm{P}=0.004)$, expected divorce following HIV disclosure (AOR=2.578; $\mathrm{p}=0.014)$ and the cultural belief that HIV was a curse (AOR=2.444; $\mathrm{p}=0.005)$. These results implied that those respondents who perceived that their partners held less gender power and control in their sexual relationships were four times more likely to disclose than those who felt their partners held more gender power and control in the relationship. The results further showed that those who believed that HIV was a curse for past mistakes were two and a half times more likely to disclose their HIV serostatus to intimate partners compared to those who held a contrary opinion.

The results further revealed that some sociocultural factors were negative predictors of self-disclosure of HIV serostatus to intimate partners. The results revealed that respondents who perceived that their male sexual partners were associated with sexual taboos such as homosexuality, rape, incest, sex with minors and extramarital sex $(\mathrm{AOR}=0.225$; $\mathrm{p}=0.001$ ) were less likely to disclose their HIV serostatus than those whose male partners were not associated with sexual taboos. Respondents who had experienced intimate partner violence (AOR=0.220; $p=0.001$ ) were less likely to disclose their HIV serostatus than those who had not experienced domestic violence The results further revealed that females who were subordinate to their male partners $(\mathrm{AOR}=0.351 ; \mathrm{p}=0.002)$ were less likely to disclose their HIV positive status compared their counterparts who were not subordinate to their male partners.
Female respondents who believed that a widow who was HIV positive should not undergo the cultural rite of wife inheritance during her widowhood (AOR=0.410; $\mathrm{p}=0.002$ ) were less likely to disclose their HIV status compared to those respondents who did not hold such perceptions. This means that female respondents, who were dependent on their male partners for support, or those who had experienced intimate partner violence and those who believed in the significance of the rite of wife inheritance after widowhood were less likely to disclose their HIV status compared to their counterparts who were not faced with similar sociocultural circumstances. However, it was observed that anticipated desertion of intimate partner $(\mathrm{AOR}=0.539 ; \mathrm{p}=0.086)$, and the belief that HIV is a death sentence on PLWHA (AOR $=0.530 ; p=0.076)$ were negative predictors of HIV disclosure, but not statistically significant. Sexual taboos associated with females such as lesbianism, rape, incest, sex with minors and extramarital sex was a positive predictor of HIV disclosure $(\mathrm{AOR}=2.746 ; \mathrm{p}=0.191)$, but they were not statistically significant.

\section{DISCUSSION}

\section{Socio-Cultural Beliefs and HIV Disclosure}

This study has established that socio-cultural factors had a significant influence on the selfdisclosure of HIV serostatus to intimate partners among People Living with HIV and AIDS. The research has shown that some of the social and cultural factors were positive predictors of HIV serostatus disclosure while others were negative predictors. The enablers of HIV disclosure were the female gender, the role of females as dependent housewives, anticipated divorce following HIV disclosure, gender inequalities in the sexual relationship and the cultural belief that HIV was a curse acted as positive predictors of HIV selfdisclosure. Conversely, intimate partner violence, the subordination of females by their male partners, the fear of exclusion from the cultural rite of wife 
inheritance during widowhood and sexual behaviour regarded as taboos were barriers or negative predictors of disclosure of HIV serostatus to intimate partners. The study found that majority of the respondents were not living with their regular sexual partners at the time of the study. This implies that they were susceptible to engaging in casual sexual relationships which may lead to increased HIV infections in the community. This finding concurs with a report by the Kenya demographic and health survey of 2014 which reported that HIV prevalence by marital status was highest among widowed, separated, divorced and the never married persons (Kenya National Bureau of Statistics (KNBS) and ICF Macro, (2014).

The study established that the cultural belief that HIV was a curse, punishment or death sentence for sexual behaviour regarded as taboos among PLWHA acted as a barrier to HIV disclosure because respondents felt condemned by their communities. This finding is consistent with the Kenya demographic and health survey of 2014 which reported that misconceptions regarding how AIDS is transmitted still exist in Kenya (KNBS \& ICF-Macro, 2014). In addition, female respondents who perceived that they would be excluded from the cultural rite of wife inheritance in the event of the death of their husbands were less likely to disclose their HIV positive status. In this study, cultural factors were found to strongly influence the decision on HIV status disclosure by PLWHA. This concurs with research by Deribe et al. (2008) which established that the anticipated fear of desertion or divorce by a male partner prevented HIV disclosure among women. Furthermore, the lack of financial support in raising children single-handedly after abandonment was a barrier to HIV disclosure. Fear of exclusion from the rite of wife inheritance was found to discourage HIV self-disclosure to intimate partners. This result may be attributed to the fear of not accessing economic support after the death of a spouse. This finding is consistent with UNESCO (2011) surveys which reported that gender inequalities reduce the opportunity to access education and formal employment of women and girls and thereby increasing their economic vulnerabilities and dependence on male partners.

\section{Gender Dynamics and HIV Disclosure}

According to Ndayala (2014), gender inequality in the sexual relationship was found to discourage HIV disclosure to sexual partners. Results showed that the perceived level of gender power control in the sexual relationship was a strong positive predictor of HIV serostatus disclosure to intimate partners. The respondents who felt that their partners held less power control in the sexual relationship were four times more likely to disclose their HIV status than those who perceived that their partners held more power in their relationship. Lack of gender equity in the sexual relationship did not promote open dialogue on sexuality issues like HIV serostatus disclosure. This study concurs with the findings by Miller et al., (2009) and Kesby (2004) which found a significant association between the male partner and high gender power control in the sexual relationship among African couples. This report is consistent with a study on family communication among Kenyan couples which reported that husbands maintained an authoritarian position in their families such that their wives were forced to strategize carefully about how to approach their spouses concerning sensitive matters such as HIV serostatus disclosure (Miller et al., 2009). Furthermore, the insubordination of females by their male partners may enhance HIV nondisclosure by female partners.

Fear of a violent reaction by male intimate partners following a seropositive disclosure was found to be a strong predictor of HIV status disclosure to intimate partners. Those who did not anticipate a violent reaction to news of their seropositive status from partners were three times more likely to disclose their HIV status compared to their counterpart who anticipated intimate partner violence after disclosure. This finding concurs with studies by Rujumba et al. (2012); Mucheto et al. (2011); Ssali (2010); Deribe et al. (2008) and Makin et al., (2007) which showed that fear of intimate partner violence was a major barrier to disclosing HIV test result. This is consistent with other studies which reported that anticipated negative partner reactions have been associated with HIV non-disclosure (Duru et al, 2006).

\section{Sexual Behaviour and HIV Disclosure}

This study has demonstrated an association between sexual behaviour and HIV serostatus 
disclosure to intimate partners. According to Ndayala (2014), sexual taboos repress HIV prevention strategies and escalate HIV transmission by creating barriers to HIV testing and serostatus disclosure. Sexual behaviour such as homosexuality, lesbianism, rape, incest and sex with minors has been associated with the spread of HIV. In some African communities, there are no age restrictions when it comes to sexual relationships. Sex with minors is condoned and considered as the norm in some cultures. Unfortunately, children have no capacity to give consent in a sexual relationship and therefore, sex with minors can promote the spread of HIV in the community. Furthermore, the sexual acts with children involve coercion which puts the minors at risk of HIV and other sexually transmitted infections.

The health belief that HIV seropositive men who have sex with minors would be cured of HIV infection is common in many African communities. This health belief is consistent with a report by Leclerc-Madlala (2002) on the virgin cleansing myth, the belief that having sex with a virgin girl cures a man of HIV/AIDS or other sexually transmitted infections. This study reported that the myth was a potential factor in infant and child sexual abuse by HIV-positive men in South Africa. This concurs with similar studies conducted in Uganda by Obbo (1993a, 1993b, 1995) which showed that there were health beliefs that frequent sex with adolescent girls could diminish the viral load of the HIV infected men, thereby escalating HIV infection among school girls. According to the United Nations Convention on the rights of the child (UNICEF, 1989) and the Children Act (Republic of Kenya, 2001), children are protected from sexual abuse. Sexual acts with minors are considered as child sexual abuse thereby putting children at risk of HIV and other sexually transmitted infections.

This study has also established that extramarital sex among female respondents was a negative predictor of HIV positive disclosure. This finding is consistent with the social expectation that marital infidelity is a sexual taboo among females, while the same is condoned among males in most cultures. This perception concurs with other studies which have reported that by social convention, women are expected to uphold high moral standards, while men can be more self-indulgent without social ramifications (Ogden \& Nyblade, 2005). This study has demonstrated that a significant proportion of respondents were in the same-sex relationship despite the belief that homosexuality and lesbianism were regarded as sexual taboos. In Kenya, HIV prevalence in men who have sex with men (MSM) is three times that of the general population (Micheni et al., 2017). Legal reports indicate that in many African countries there are stringent laws governing samesex relationships (The Law Library of Congress, 2014) This is consistent with the applicable law in Kenya where homosexuality and gay marriages are illegal and punishable on conviction to a term of 14 years' imprisonment. (Republic of Kenya, 2012).

\section{CONCLUSION}

This study has established that socio-cultural factors have a significant influence on the selfdisclosure of HIV serostatus to intimate partners among People Living with HIV and AIDS. The findings demonstrated that only half of the respondents had disclosed their HIV serostatus to their intimate partners. This implies that the other half of the respondents were less likely to disclose their HIV serostatus. The results revealed that the female gender, the role of females as dependent housewives, anticipated divorce following HIV disclosure, gender inequalities in the sexual relationship and the cultural belief that HIV was a curse were positive predictors of HIV selfdisclosure. However, intimate partner violence, the subordination of females by their male partners and the fear of exclusion from the cultural rite of wife inheritance during widowhood and sexual taboos associated with the sexual behaviour of PLWHA such as homosexuality, rape, incest, sex with minors and extramarital sex were negative predictors of disclosure of HIV serostatus to intimate partners. This implies that some of the socio-cultural factors had a significant influence on the non-disclosure of HIV positive status, thereby putting intimate partners at risk of HIV infection. It was recommended that there was need to promote community dialogues on HIV and AIDS, causes, prevention, voluntary counselling and testing, selfdisclosure of HIV serostatus and how to live positively with the condition. These strategies may 
reduce the socio-cultural barriers to self-disclosure of HIV serostatus and in turn decrease the spread of HIV infections within the community.

\section{ACKNOWLEDGMENTS}

We wish to appreciate the support from the participants of this study.

\section{AUTHORS' CONTRIBUTIONS}

This article is based on a PhD thesis conducted by the first author under the supervision of the second author. Both authors contributed to the writing of this article.

\section{REFERENCES}

Action Aid International Kenya (2009). Extent and impact of stigma and discrimination on women and children infected and affected by HIV/AIDS. Nairobi: Action Aid.

Deribe, K., Woldemichael, K., Wondafrash, M., Haile, A., \& Ambedir, A. (2008). Disclosure experience and associated factors among HIV positive men and women clinical service users in South West Ethiopia. BMC Public Health, 8: 81 .

Duru, O. K., Collins, R. L., Ciccarone, D. H., Morton, S. C., Stall, R., Beckman, R., Miu, A., $\&$ Kanouse, D. E. (2006). Correlates of sex without serostatus disclosure among a national probability sample of HIV patients. AIDS and behaviour, $\quad 10 \quad$ (5), 495-507. https://doi.org/10.1007/s10461-006-9089-3

Kenya National Bureau of Statistics \& ICF Macro, (2014). Kenya Demographic and Health Survey, 2014. Calverton, Maryland: KNBS and ICF Macro.

Kesby, M., (2004). Participatory diagramming and the ethical and practical challenges of helping Africans themselves to move HIV work "beyond epidemiology. In: Kali-peni, E, Craddock, J., Oppong, R., Ghosh, J., (Eds.). HIV and AIDS in Africa: Beyond Epidemiology (pp. 217-228). Malden, M. A: Blackwell.
Kim, B., France, L., Remi, S., Annie, S., Bruno, S. \& Dray-Spira, R. (2007). Factors Correlated with disclosure of HIV infections in the French Antilles and French Guiana: Results from the ANRS-ENRS-EN13-VESPA-DFA Study. AIDS, 21 (Suppl. 1), S89-S94.

Leclerc-Madlala, S. (2002). On the virgin cleansing myth: gendered bodies, AIDS and ethnomedicine. Afr. J. AIDS Res. 2002; 1 (2): 87-95. Retrieved from: doi:10.2989/16085906.2002.9626548.

Leclerc-Madlala, S. (2008). Age-disparate and intergenerational sex in southern Africa: the dynamics of hyper-vulnerability. AIDS, 22 (Suppl. 40), 17-25.

Liu, H., Hu Z., Li, X., Stanton, B., Naar-King, S. \& Yang, H. (2006). Understanding the interrelationships among HIV related stigma, concern about HIV infection, and intent to disclose HIV serostatus: a pre-test-post-test study in rural area of Eastern China. AIDS Patient Care and STDs. 2006; 20 (2), 133-142.

Makin, J. D., Brian, W., C., Maretha, J. V., Kathleen, J. S., Sharon, N. \& Bridget, J. (2007). Factors affecting Disclosure in South African HIV-Positive Pregnant Women. AIDS Patient Care 22, (11), 907-916.

Mbonu, N.C, Van den Borne, B. \& De Vries, N.K. (2009). Stigma of People with HIV/AIDS in Sub-Saharan Africa: A Literature Review. $J$ Trop Med., 2009: 145891. doi:10.1155/2009/145891

Micheni, M., Kombo, B.K., Secor, A., Simoni, J.M., Operio, D., Van der Elst, E.M., Mugo, P., Kanungi, J., Sanders, E.J. \& Graham, S.M. (2017). Health provider views on improving antiretroviral therapy adherence among men who have sex with men in coastal Kenya AIDS Patient Care and STDs, Vol. 31, Number 3, 2017 Available at DOI: 10.1089/apc.2016.0213.

Miller, A.N. \& Rubin, D. L. (2007). Factors Leading to Self-Disclosure of a Positive HIV Diagnosis in Nairobi, Kenya. People Living 
With HIV/AIDS in the Sub-Sahara. Qualitative Health Research, Vol. 17, No. 5, 586-598.

Miller, A.N., Golding, L., Ngula, K., Wambua, M. A., Kizito, M. N., Mutua, E., et al. (2009). Couples communication on sexual and relational issue in Machakos District, Kenya. African Journal of AIDS Research, 8, 51-60.

Mucheto, P., Chadambuka, A., Shambira, G., Tshimanga, M., Gombe, N., \& Nyamayaro, W. (2011). Determinants of nondisclosure of HIV status among women attending the prevention of mother to child transmission programme, Makonde district, Zimbabwe, 2009. Pan African Medical Journal, 8(1).

Ndayala, P. D. (2014). Predictors of HIV Self Disclosure to Sexual Partners by Sero-Positive Adults in Informal Settlements: A Case of Central Division, Nairobi County, Kenya (Doctoral dissertation, Kenyatta University).

Ndiaye, C., Boileau, C., Zunzunegui, M.V., Koala, S. Abaubacrine, S.A., Niamba, P., Nguyen, V.K. \& Rashed, S. (2008). Gender-related factors influencing HIV serostatus disclosure in patients receiving HAART in West Africa. World Health \& Population, 10 (3): 43-54. Retrieved from https://europepmc.org/article/med/19369822

Ngula, K. \& Miller, A. N. (2010). Self-disclosure of HIV seropositivity in Kenya by HIVpositive Kamba men and their families, Southern Communication Journal, 75: 4, 328348, DOI: 10.1080/1041794x.2010.504443

Norman, A., Chopra, M. \& Kadiyala, S. (2005). HIV Disclosure in South Africa: Enabling the Gateway to Effective Response. Accessed from https://www.researchgate.net/publication/2555 72259.

Obbo, C. (1993a). HIV transmission through social and geographical networks in Uganda. Social Science and Medicine, 36 (7): 949-955.

Obbo, C. (1993b). HIV transmission: Men are the solution. Population and Environment. 14 (3): 211-243.
Obbo, C. (1995). Gender, age and class: Discourses on HIV transmission and control in Uganda. In: H. T. Brummelhuis and G. Herdt (Eds.), Culture and sexual risk: anthropological perspectives on AIDS, Amsterdam: Gordon and Breach: 79-98.

Ogden, J. \& Nyblade, L., (2005). Common at its core: HIV-related stigma across contexts. International Center for Research on Women. Accessed from www.icrw.org.

Republic of Kenya. (2001). Children Act, Laws of Kenya, CAP. 141 (Revised, 2012). Available at https://kenyalaw.org.

Republic of Kenya. (2012). Penal code of 1930, Laws of Kenya, CAP. 63 (Revised, 2012). Available at https://kenyalaw.org.

Rujumba, J. Neema, S., Byamugisha, R., Tylleskär, T., Tumwine, J.K. \& Heggenhougen, H.K. (2012). Telling my husband I have HIV is too heavy to come out of my mouth: pregnant women's disclosure experiences and support needs following antenatal HIV testing in eastern Uganda. J. Int. AIDS Soc. 15 (2): 17429. doi:10.7448/ias.15.2.17429.

Serovich J. M., Ji-Young L. \& Mason L. T., (2008). A retest of two HIV disclosure theories. Health social work, 33 (1): 23-31.

Simbayi, L., Kalichman, S., Strebel, A., Cloete, A., Henda, N. \& Mqeketo, A. (2006). Disclosure of HIV status to sex partners and sexual risk behaviours among HIV positive men and women, Cape Town, South Africa. Sex Transmitted Infections, 83:29-34.

Smith, R., Rossetto, K., \& Peterson, L., (2008). A meta-analysis of disclosure of one's HIVpositive status, stigma and social support. AIDS Care, 20 (10): 1266-1275.

Ssali, S. N., Atuyambe, L., Tumwine, C., Segujja, E., Nekesa, N., Nannungi, A. \& Wagner, G. (2010). Reasons for disclosure of HIV status by people living with HIV/AIDS and HIV care in Uganda. An exploratory study. AIDS Patients Care and STDs. 24 (10), 675-681. 
The Law Library of Congress: Global legal research centre (2014). Laws on homosexuality in African nations. Accessed from, https://www.law.gov.

Turan, J. M., Miller S., Bukusi, E. A., Onono, M., William, L., Miller, S. \& Cohen, C.R., (2011). HIV/AIDS stigma and refusal of HIV testing among pregnant women in rural Kenya: Results from the MAMAS Study. AIDS Behaviour; 15:1111-1120.

Turan, J. M., Miller, S., Bukusi, E. A., Sande, J. \& Cohen, C.R. (2008). HIV/AIDS and maternity care in Kenya: how fears of stigma and discrimination affect uptake and provision of labour and delivery services. AIDS Care; 20 (8): 938-45.

UNAIDS. (2003). Fact sheet on stigma and discrimination. Retrieved 17, August 2020 from https://unaids.org.

UNAIDS. (2018). HIV and AIDS: Country Report - Kenya. Retrieved 14, August 2020 from https://unaids.org.

UNAIDS. (2020). Global AIDS Update-2020. Retrieved 14, August 2020 from https://unaids.org.

UNESCO, (2011). Global Education Digest Paris: UNESCO.

UNICEF (1989). United Nations Convention on the rights of the child. Accessed from www.unicef.org/crc.

Varga, C., Sherman, G. \& Jones, S., (2006): HIVdisclosure in the context of vertical Transmission: HIV-positive mothers in Johannesburg, South Africa. AIDS Care, 18: 8, 952-960.

Vu, L., Andrinopoulos, K., Mathews, C., Chopra, M., Kendall, C. \& Esiele, T.P. (2012). Disclosure of HIV status to sex partners among HIV-infected men and women in Cape Town, South Africa. AIDS Behaviour, 16 (1): 132138.

Walcott, M.M., Hatcher, A.M., Kwena, Z. \& Turan, J.M. (2013). Facilitating HIV status disclosure for pregnant women and partners in rural Kenya: A qualitative study. BMC Public Health 13, 1115 (2013). https://doi.org/10.1186/14712458-13-1115.

Wiener, L. S., Battles, H. B. \& Wood, L. V, (2007). A longitudinal Study of Adolescents with perinatally or Transfusion Acquired HIV infection: Sexual knowledge, risk reduction self-efficacy and sexual behaviour AIDS Behaviour 11; 471 -478.

Wolfe, W.R., Weiser, S.D. \& Bangsberg, D. R. (2006). Effects of HIV related stigma among an early sample of patients receiving antiretroviral therapy in Botswana. AIDS Care, 2006; 18: 931-933. [PubMed].

World Health Organization (WHO), (2008). Towards Universal Access: Scaling up priority HIV/AIDS interventions in the health sector: Progress report. Geneva: WHO. 